\title{
Distribution of hydrophilic and lipophilic antibacterial drugs in skim milk, cream, and casein
}

\author{
Z. Ozdemir, ${ }^{1}$ B. Tras, and K. Uney \\ Department of Pharmacology and Toxicology, Faculty of Veterinary Medicine, University of Selcuk, 42031 Konya, Turkey
}

\begin{abstract}
This study determined the distribution of drugs to different milk fractions according to their physicochemical properties. Hydrophilic drugs tend to concentrate in skim milk, whereas lipophilic drugs tend to concentrate in cream. The concentration of a drug in casein is related to its degree of binding to milk proteins. Thus, we aimed to determine whether withdrawal time in whole milk differs from that in cream, casein, and skim milk. Amoxicillin and tylosin were selected as prototype hydrophilic and lipophilic drugs, respectively. The study was conducted in vitro and in vivo to determine whether in vitro conditions reflect the distribution of drugs in the different milk fractions in vivo. The in vivo study was conducted using a crossover design on 6 healthy Holstein dairy cattle. First, amoxicillin (i.m., single dose, $14 \mathrm{mg} / \mathrm{kg}$ ) was administered to cows. Following a 1-wk washout period, tylosin (i.m., single dose, $15 \mathrm{mg} / \mathrm{kg}$ ) was administered. Concentrations of amoxicillin and tylosin in milk and milk fractions were measured using HPLC-UV. In the in vitro study, 0.04 to $400 \mu \mathrm{g} / \mathrm{g}$ of amoxicillin and 0.05 to $50 \mu \mathrm{g} / \mathrm{g}$ of tylosin were spiked to drug-free milk and the concentrations in milk and milk fractions were measured. In addition, the percentage of total protein in milk and milk fractions was determined. Amoxicillin accumulated more in skim milk than in cream and casein, both in vitro $(92 \%)$ and in vivo (73\%, skim milk-to-whole milk ratio). The distribution of tylosin in whole and skim milk was similar to that of amoxicillin in the in vitro study, in contrast to the accumulation of tylosin in cream seen in vivo. However, the accumulation ratio of tylosin in cream was lower than expected. By either method, tylosin was less concentrated in casein than in skim milk and cream. The percentage of total protein was similar in skim milk and whole milk and higher than in cream. Thus, amoxicillin accumulates less in cream and casein, suggesting that these fractions would pose a lower risk
\end{abstract}

Received March 19, 2018.

Accepted August 21, 2018.

${ }^{1}$ Corresponding author: zynp.ozdmr@windowslive.com to the consumer. Tylosin was still present at the maximum residue limit $(50 \mu \mathrm{g} / \mathrm{kg}) 24 \mathrm{~h}$ after injection in the casein fraction and $48 \mathrm{~h}$ after injection in the cream fraction.

Key words: milk fraction, hydrophilic, lipophilic, accumulation, drug

\section{INTRODUCTION}

Antibacterial drugs are used to treat infectious diseases and for prophylaxis and metaphylaxis (Phillips et al., 2004). The irrational and widespread use of antibiotics leads to the presence of drug residues in animal food products. In addition to economic losses, drug residues in animal products cause health problems as well as the development and spread of antibiotic resistance in bacteria. After the administration of drugs to lactating animals, legally mandated withdrawal times can necessitate the disposal of milk, leading to economic loss (McEwen and Fedorka-Cray, 2002).

Passage of a drug into milk depends on factors related to the drug (protein binding, route of administration, physicochemical properties, and drug-drug and drug-nutrient interactions) and to the living organism (breed, species, lactation period, parity, disease, and nutrition) (Hervada et al., 1978; NRC, 1988). Drugs can reside in one or more milk fractions bound to protein such as casein, dissolved within fat globules, or free in the aqueous medium (Craig and Stitzel, 2004). Drug distribution to the different fractions of milk varies according to both the route of administration and the dose (Ziv and Rasmussen, 1975; Power et al., 2013a). In particular, protein binding degree and lipophilicity play an important role in drug distribution in the milk (Agatonovic-Kustrin et al., 2002). The passage ratio of hydrophilic drugs, such as $\beta$-lactam and aminoglycoside, to udder tissue are low, whereas that of lipophilic drugs, such as macrolides and fluoroquinolones are high (Benchaoui, 2010). Drugs with a high degree of binding to milk proteins are found at high concentrations in milk, whereas drugs with a high degree of binding to plasma proteins have a low distribution to milk (Agatonovic-Kustrin et al., 2002; Gehring and Smith, 2006). 
Although the percentage of casein in milk protein varies according to species, casein makes up $80 \%$ of cow milk protein (NRC, 1988). Some food supplements used in human health, such as mineral additives, antimicrobial peptides, and antioxidants, contain pure casein, providing another unexpected source of drugs as a result of contaminated milk (Phelan et al., 2009).

Amoxicillin is a semi-synthetic bactericidal antibiotic in the group of aminopenicillins. In veterinary medicine, it is frequently used in combination with clavulanic acid, which is a $\beta$-lactamase enzyme inhibitor (Yeoman, 1977). Amoxicillin is a hydrophilic drug, and its binding degree to plasma protein is approximately $30 \%$ (Gehring and Smith, 2006). It is metabolized into amoxicilloic acid, which causes allergic reactions (Reyns et al., 2008). The withdrawal time for amoxicillin in milk is $4 \mathrm{~d}$ ( 8 milkings) after parenteral administration, and the maximum residue limit (MRL) established for amoxicillin in cow milk is $4 \mu \mathrm{g} / \mathrm{kg}$ (European Union, 2010). The administration of a high dose of amoxicillin trihydrate $(22 \mathrm{mg} / \mathrm{kg}$ of $\mathrm{BW})$ to cows was not above the tolerance level ( $>10 \mathrm{ppb})$ stated by the Food and Drug Administration (FDA) in milk during the withdrawal time (Anderson et al., 1996).

Tylosin, a weak base with lipophilic properties, is an antibacterial drug used in veterinary medicine (Dudriková et al., 1999). Twenty-five to $47 \%$ of tylosin binds to plasma protein and passes readily into milk. Its concentration may be 5 times higher in milk than in plasma (Avci and Elmas, 2014). The withdrawal time for milk is $4 \mathrm{~d}$ (8 milkings) after parenteral administration, and the MRL established for tylosin in cow milk is $50 \mu \mathrm{g} / \mathrm{kg}$ (European Union, 2010).

Although many studies have determined the presence of amoxicillin and tylosin residues in milk, there are no data on the distribution of amoxicillin and tylosin in milk fractions (Luo et al., 1997; Dudriková et al., 1999; Khaskheli et al., 2008; Wang et al., 2008; MartínezHuelamo et al., 2009; Avci and Elmas, 2014; Li et al., 2014). The aims of this study were (1) to determine the distribution of amoxicillin and tylosin in cream, skim milk, and casein and whether the withdrawal time for different fractions of milk differs according to the physicochemical properties of the drugs; and (2) to determine whether the in vitro assay accurately reflects the distribution of drugs in the different fractions of milk in vivo.

\section{MATERIALS AND METHODS}

\section{Animals}

The study was carried out on 6 healthy dairy cows (Holstein, 450-500 kg, 2-4 yr, mean daily milk yield of $20-25 \mathrm{~kg}$ ), with an SCC of $\leq 250,000$ cells $/ \mathrm{mL}$ in their milk assessed using microscopy. The animals were maintained under the same management and feeding conditions for $1 \mathrm{mo}$ to prevent the administration of any drugs. During the study, cows were fed ad libitum with concentrate mix, clover, straw, and water. This study was approved by the Ethics Committee of the Selcuk University, Faculty of Veterinary Medicine (no. 2016/056).

\section{Study Design}

The study was conducted in 2 parts: in vivo and in vitro. The in vivo study was performed using a crossover design. The amoxicillin and tylosin doses used in the study were determined by considering the doses used in other studies related to amoxicillin $(10-25 \mathrm{mg} / \mathrm{kg}$ of BW; Atef et al., 1991; Al Wabel, 2008; Avci and Elmas, 2014) and tylosin (10-17.5 mg/kg of BW; Craigmill et al., 1992; Carceles et al., 1995a,b; Escudero et al., 1996; Elsheikh et al., 1999; Fernandez et al., 2007). Each animal was administered a single i.m. injection of amoxicillin (Synulox, Pfizer, NY) at a dose of 14 $\mathrm{mg} / \mathrm{kg}$ of $\mathrm{BW}$ into the dorsolateral region of the neck. Milk samples were collected before (0) and at 1, 3, 6, 9, $12,24,48,72,96,120$, and $144 \mathrm{~h}$ after administration. Frequent sampling was performed to account for the sensitivity of the analysis method and the lack of data on the passage ratio of amoxicillin into milk.

After a 1-wk washout period, tylosin (Tylan 200, Eli Lilly, Indianapolis, IN) was administered to the same cattle using the same administration route at a dose of $15 \mathrm{mg} / \mathrm{kg}$ of BW. Milk samples were collected before (0) and at 24, 48, 72, 96, 120, and $144 \mathrm{~h}$ after administration. Milk samples $(50 \mathrm{~mL})$ from amoxicillin and tylosin treatments were collected into sterile tubes and stored at $-80^{\circ} \mathrm{C}$ until analysis.

In the in vitro stage of the study, different amounts of amoxicillin $(0.04,0.4,4,40$, and $400 \mu \mathrm{g} / \mathrm{g})$ and tylosin $(0.05,0.5,5$, and $50 \mu \mathrm{g} / \mathrm{g})$ were spiked to drug-free milk samples obtained from the cattle before the in vivo study. These levels were determined according to the MRL and maximum drug concentration (Cmax) in milk of amoxicillin (European Union, 2010; Li et al., 2014) and tylosin (European Union, 2010; Avci and Elmas, 2014), respectively.

\section{Separation of Whole Milk to Milk Fractions}

In the in vitro study, whole milk was separated to skim milk, cream, and casein after incubation at $37^{\circ} \mathrm{C}$ for $30 \mathrm{~min}$. Cream was separated from whole milk (50 $\mathrm{mL}$ ) using centrifugation at $4,000 \times g$ for $45 \mathrm{~min}$ at $35^{\circ} \mathrm{C}$, with minor modifications of the method reported 
by Morton (1954). After removing the cream, the skim milk was vortexed to resuspend the milk proteins.

Casein was obtained using minor modifications of the method reported by Ziv and Rasmussen (1975) and Morton (1954). Casein was separated from skim milk $(10 \pm 0.1 \mathrm{~g})$ following centrifugation at $4,000 \times g$ for 45 min 3 times at $2^{\circ} \mathrm{C}$. The casein layer was obtained by cutting the vial with a scalpel blade. Casein was washed 3 times in distilled water and then dried on absorbent paper.

\section{Analytical Procedure}

Amoxicillin and tylosin concentrations in whole and skim milk, cream, and casein were determined using a HPLC system (Shimadzu, Tokyo, Japan) consisting of a pump (LC-20AT with CBM-20A system controller), a degasser (DGU-14A) to pump the mobile phase, an autosampler (SIL 20A), and a column oven (CTO 10A). The HPLC procedures for amoxicillin and tylosin were based on the methods reported by Karageorgou and Samanidou (2011) and Avci and Elmas (2014), respectively.

Amoxicillin was detected using an SPD-10A UVvisible detector (Shimadzu) set at $225 \mathrm{~nm}$. The column and autosampler were kept at room temperature. The reverse-phase chromatography was performed using an analytical Gemini C18 column $(250 \mathrm{~mm} \times 4.6 \mathrm{~mm}$ i.d., $5 \mu \mathrm{m}$; Phenomenex, Torrance, CA) with an injection volume of $50 \mu \mathrm{L}$ and a flow rate of $1 \mathrm{~mL} / \mathrm{min}$. The mobile phase was a 92:8 ( vol/vol) mixture of $0.1 \%$ trifluoroacetic acid (Merck, Darmstadt, Germany) and acetonitrile (VWR, Fontenay sous Bois, France).

Tylosin was detected using the SPD-10A UV-visible detector (Shimadzu) set at $287 \mathrm{~nm}$. The column and autosampler were kept at $40^{\circ} \mathrm{C}$ and room temperature, respectively. Reverse-phase chromatography was performed using an analytical Gemini C18 column (Phenomenex) with an injection volume of $50 \mu \mathrm{L}$ and a flow rate of $1 \mathrm{~mL} / \mathrm{min}$. The mobile phase was a $65: 35$ (vol/ vol) mixture of $0.1 \%$ trifluoroacetic acid and acetonitrile.

A $1 \mathrm{mg} / \mathrm{mL}$ stock solution of amoxicillin was prepared in 20\% acetonitrile. Amoxicillin calibration standards for all milk fractions were prepared fresh daily in the range of 0.003 to $400 \mu \mathrm{g} / \mathrm{g}$. The quality control (QC) samples with amoxicillin at low $(0.4 \mu \mathrm{g} / \mathrm{g})$, medium (4 $\mu \mathrm{g} / \mathrm{g})$, and high $(40 \mu \mathrm{g} / \mathrm{g})$ concentrations were freshly prepared for milk and milk fractions to evaluate the recovery, accuracy, and precision of this HPLC method.

A $1 \mathrm{mg} / \mathrm{mL}$ stock solution of tylosin was prepared in $50 \%$ methanol (VWR). Tylosin calibration standards for all milk fractions were prepared fresh daily in the range of 0.008 to $50 \mu \mathrm{g} / \mathrm{g}$. The QC samples with tylosin at low $(0.5 \mu \mathrm{g} / \mathrm{g})$, medium $(5 \mu \mathrm{g} / \mathrm{g})$, and high $(50 \mu \mathrm{g} / \mathrm{g})$ concentrations were freshly prepared for milk and milk fractions to evaluate the recovery, accuracy, and precision of this HPLC method.

\section{Sample Preparation Procedure}

Whole or skim milk samples (10 g $\pm 0.1 \mathrm{~g})$ were added to $50-\mathrm{mL}$ centrifuge tubes. Cream or casein samples $(1 \pm 0.01 \mathrm{~g})$ and ultra-pure water $(9 \mathrm{~mL})$ were added to centrifuge tubes $(50 \mathrm{~mL})$.

Amoxicillin was extracted from whole and skim milk, casein, and cream using $1 \mathrm{M} \mathrm{HCl}(10 \mathrm{~mL}$, Carlo Erba, Barcelona, Spain) and the supernatants underwent solid-phase extraction using Strata X cartridges (Phenomenex). The Strata X cartridges were activated with $3 \mathrm{~mL}$ of methanol and $3 \mathrm{~mL}$ of distilled water. After samples were passed through the system, the cartridge was cleaned with $3 \mathrm{~mL}$ of distilled water to decrease matrix interference. After 1 min of drying, the analytes were eluted with $1 \mathrm{~mL}$ of $0.1 \%$ trifluoroacetic acid and acetonitrile $(92: 8, \mathrm{vol} / \mathrm{vol})$.

Tylosin was extracted from whole and skim milk, casein, and cream using $30 \mathrm{~mL}$ of acetonitrile, and the supernatants underwent solid-phase extraction using Strata X cartridges. The Strata X cartridges were activated with $10 \mathrm{~mL}$ of methanol and $10 \mathrm{~mL}$ of distilled water. After samples were passed through the system, the cartridge was cleaned with $10 \mathrm{~mL}$ of distilled water followed by $10 \mathrm{~mL}$ of $25 \%$ acetonitrile to decrease matrix interference. After $1 \mathrm{~min}$ of drying, the analytes were eluted with $1 \mathrm{~mL}$ of $0.1 \mathrm{M}$ ammonium acetate (Merck).

\section{Method Validation}

Selectivity of the methods was evaluated by analyzing blank samples of whole milk, skim milk, cream, and casein spiked with amoxicillin and tylosin. The linearity of the methods was evaluated using a calibration curve in the range of 0.003 to $400 \mu \mathrm{g} / \mathrm{g}$ amoxicillin and 0.008 to $50 \mu \mathrm{g} / \mathrm{g}$ tylosin for milk and milk fractions. Six calibration curves constructed on 6 separate days were analyzed to evaluate the linearity of each calibration curve. The limits of detection (LOD) and quantification (LOQ) were determined using signal-tonoise ratio evaluations of samples with 0.001 to 0.05 $\mu \mathrm{g} / \mathrm{g}$ amoxicillin and tylosin. Six replicates of each level of QC samples for amoxicillin and tylosin were assayed in one run for the intraday experiment. Six replicates of each level of QC samples for amoxicillin and tylosin were assayed on 6 different days for the interday experiment. The intra- and interday precision and accuracy of the assays were determined using percent coefficient 
of variation $(\mathbf{C V})$ and percent bias values, respectively. The CV were calculated as follows: CV $(\%)=(\mathrm{SD} /$ mean $) \times 100$. The percent bias values from the theoretical concentration were calculated using the following equation: Bias $(\%)=[$ (calculated concentration - theoretical concentration)/theoretical concentration] $\times 100$. Acceptance criteria for accuracy and precision were as $\mathrm{CV}<15 \%$ and bias within $\pm 15 \%$, respectively. For calculation of absolute recoveries of amoxicillin and tylosin, QC samples for amoxicillin and tylosin were prepared at low, medium, and high concentrations. Six replicates of each QC sample for amoxicillin and tylosin were extracted using the above-mentioned sample preparation methods and injected into the HPLC system. The concentrations of amoxicillin and tylosin were determined using the linear regression of the analytical standard curve. The recoveries were calculated by comparing the observed concentration with the initial concentrations.

\section{Determination of Total Protein}

The analysis of protein in whole milk, skim milk, and cream was performed according to the Kjeldahl method (AOAC International, 2000) using a fully automatic protein device (OPSIS KjelROC Analyzer, Furulund, Sweden).

\section{Statistical Analyses}

The study data were evaluated for normal distribution. Friedman 2-way ANOVA was performed for non-normally distributed data. Comparisons of intragroup percentage distribution in milk fractions were evaluated based on sampling times in the in vivo stage and concentrations in the in vitro stage. All data were reported as mean \pm standard deviations. Statistical analysis was performed using SPSS 23.0 software (IBM Corp., Chicago, IL); $P$-values of $<0.05$ were considered significant.

\section{RESULTS}

\section{Validation}

Validation results for amoxicillin and tylosin in whole milk, skim milk, cream, and casein are presented in Table 1. At all levels, precision values for amoxicillin and tylosin were $<15 \%$. The accuracy values of amoxicillin and tylosin detection were $\pm 15 \%$. The LOD and LOQ, respectively, of amoxicillin were 0.01 and 0.02 $\mu \mathrm{g} / \mathrm{g}$ for whole milk, skim milk, and cream. These limits for casein were 0.0015 and $0.003 \mu \mathrm{g} / \mathrm{g}$, respectively. The LOD and LOQ, respectively, of tylosin were 0.004 and $0.008 \mu \mathrm{g} / \mathrm{g}$ for whole milk, skim milk, cream, and casein. The mean extraction recoveries of amoxicillin and tylosin from milk and milk fractions were $>82$ and $>88 \%$, respectively.

\section{Distribution of Drugs into Milk Fractions}

The percent distribution of amoxicillin in milk fractions from the in vitro and in vivo studies is presented in Table 2. The amoxicillin concentration was higher in skim milk than in cream and casein in both parts of the study. The amoxicillin concentration was $<\mathrm{LOQ}$ in milk and its fractions at $\geq 24 \mathrm{~h}$. In addition, when amoxicillin was spiked at $0.04 \mu \mathrm{g} / \mathrm{g}$, the level in cream and casein was less than LOQ.

The percent distribution of tylosin in the milk fractions from the in vitro and in vivo studies is presented in Table 3. The tylosin concentration in whole milk differed from that in cream, skim milk, and casein. In the in vivo study, the concentration of tylosin was higher in cream than in skim milk and casein. Tylosin concentration was $<$ LOQ in milk and its fractions at $\geq 120 \mathrm{~h}$. In addition, when tylosin was spiked at $0.05 \mu \mathrm{g} / \mathrm{g}$, the level in cream and casein was less than LOQ. The in vitro data showed that the tylosin concentration was approximately equal to that in whole milk and higher ( $\sim 15$ fold $)$ than in cream.

The percentage distributions of amoxicillin and tylosin in skim milk, cream, and casein are illustrated in Figures 1a and 1b, respectively. Amoxicillin and tylosin were distributed to cream and casein to greater degree in vivo than in vitro. Tylosin was distributed more in skim milk when assessed in in vivo than in vitro. The accumulation ratios of amoxicillin and tylosin in casein varied according to concentration in both stages of the study.

\section{Percentage of Total Protein}

Percentage of total protein was determined to be 3.10 $\pm 0.10,3.19 \pm 0.11$, and $1.68 \pm 0.07 \%$ in whole milk, skim milk, and cream, respectively.

\section{DISCUSSION}

This study examined the difference in drug distribution in vivo versus in vitro to assess the appropriateness of drug withdrawal times and the risk associated with various milk fractions. It is important to understand the distribution of drugs in milk in order to use the different fractions of milk during drug withdrawal in dairy animals. There is limited research on the accumulation of drugs in different fractions of milk such as skim milk, cream, and casein. Thus, research is needed to prevent 
OZDEMIR ET AL.

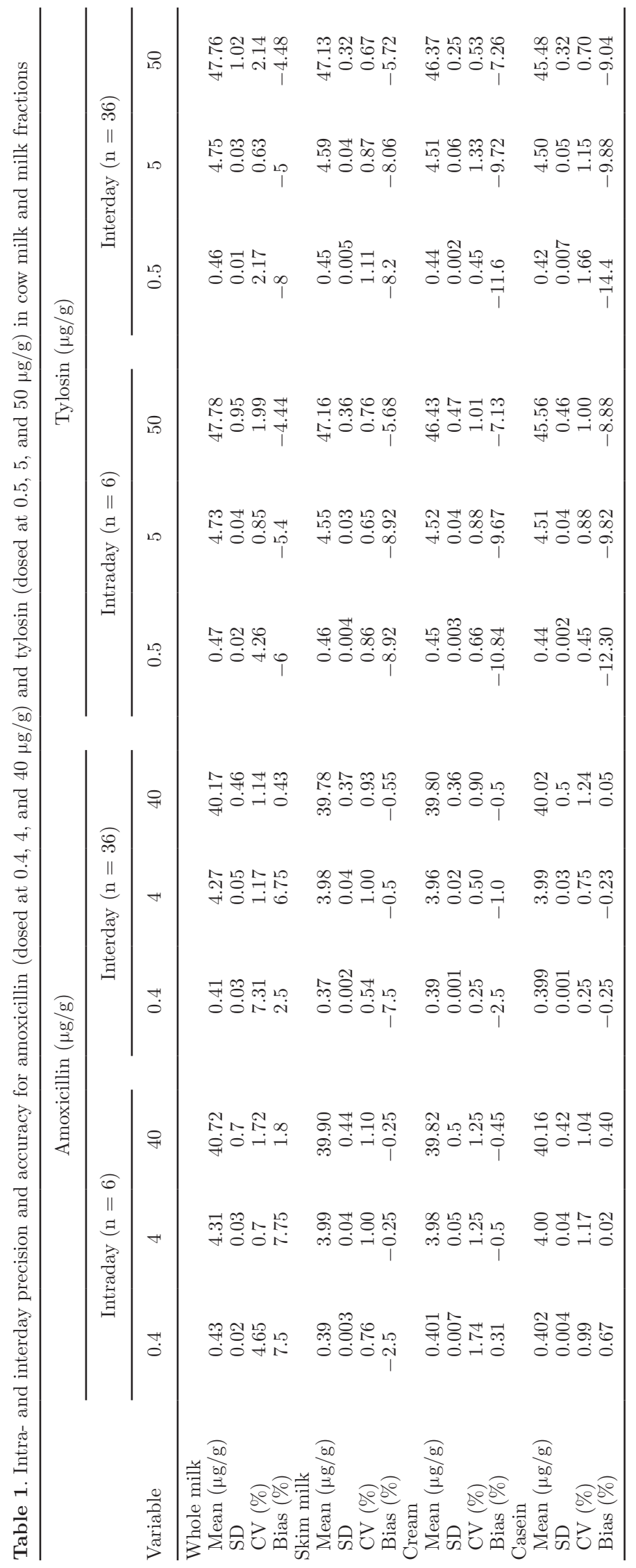


Table 2. Distribution (\%; mean \pm SD) and amount ${ }^{1}(\mu \mathrm{g}$; mean $\pm \mathrm{SD}$ ) of amoxicillin in milk fractions following its addition to whole milk at different concentrations (in vitro study) or at different sampling times following a single intramuscular dose (14 mg/kg; in vivo study)

\begin{tabular}{|c|c|c|c|c|c|c|c|c|}
\hline \multirow[b]{2}{*}{ Variable } & \multirow[b]{2}{*}{$\mathrm{n}$} & \multirow{2}{*}{$\begin{array}{l}\text { Whole } \\
\text { milk }\end{array}$} & \multicolumn{6}{|c|}{ Fraction } \\
\hline & & & Skim milk $(\mu \mathrm{g})$ & Skim milk (\%) & Cream ( $\mu g)$ & Cream $(\%)$ & Casein $(\mu \mathrm{g})$ & Casein $(\%)$ \\
\hline 0.04 & 9 & $0.04 \pm 0.001$ & $0.035 \pm 0.006$ & $87.53 \pm 3.19^{\mathrm{a}}$ & $<\mathrm{LOQ}^{2}$ & $<\mathrm{LOQ}$ & $<\mathrm{LOQ}$ & $<\mathrm{LOQ}$ \\
\hline 0.4 & 9 & $0.44 \pm 0.01$ & $0.39 \pm 0.02$ & $88.63 \pm 2.28^{\mathrm{ab}}$ & $0.05 \pm 0.01$ & $11.37 \pm 2.40^{\mathrm{ab}}$ & $0.003 \pm 0.000$ & $0.68 \pm 0.09^{\mathrm{a}}$ \\
\hline 4 & 9 & $4.33 \pm 0.01$ & $3.98 \pm 0.07$ & $91.30 \pm 2.25^{\mathrm{b}}$ & $0.35 \pm 0.09$ & $8.06 \pm 2.37^{\mathrm{b}}$ & $0.03 \pm 0.004$ & $0.69 \pm 0.13^{\mathrm{a}}$ \\
\hline 40 & 9 & $40.74 \pm 0.95$ & $39.90 \pm 0.83$ & $97.35 \pm 0.87^{\mathrm{c}}$ & $0.84 \pm 0.33$ & $2.05 \pm 0.92^{c}$ & $0.32 \pm 0.002$ & $0.78 \pm 0.09^{\mathrm{a}}$ \\
\hline \multicolumn{9}{|c|}{ Sampling time $(\mathrm{h})$} \\
\hline 1 & 6 & $0.06 \pm 0.01$ & $0.05 \pm 0.01$ & $76.19 \pm 13.37^{\mathrm{abc}}$ & $0.02 \pm 0.01$ & $25.10 \pm 14.09^{\mathrm{abc}}$ & $0.05 \pm 0.01$ & $81.75 \pm 17.57^{\mathrm{a}}$ \\
\hline 3 & 6 & $0.26 \pm 0.02$ & $0.22 \pm 0.02$ & $82.29 \pm 7.07^{\mathrm{a}}$ & $0.05 \pm 0.02$ & $18.67 \pm 7.45^{\mathrm{a}}$ & $0.017 \pm 0.002$ & $6.72 \pm 1.15^{\mathrm{b}}$ \\
\hline 6 & 6 & $0.36 \pm 0.03$ & $0.27 \pm 0.03$ & $75.09 \pm 6.46^{\mathrm{b}}$ & $0.10 \pm 0.03$ & $26.25 \pm 6.81^{\mathrm{b}}$ & $0.04 \pm 0.003$ & $10.19 \pm 1.72^{\mathrm{c}}$ \\
\hline 9 & 6 & $0.09 \pm 0.00$ & $0.06 \pm 0.01$ & $67.66 \pm 8.29^{c}$ & $0.03 \pm 0.01$ & $34.08 \pm 8.73^{\mathrm{c}}$ & $0.016 \pm 0.002$ & $17.66 \pm 3.25^{\mathrm{d}}$ \\
\hline 12 & 6 & $0.06 \pm 0.01$ & $0.04 \pm 0.01$ & $64.43 \pm 3.10^{\mathrm{c}}$ & $0.02 \pm 0.00$ & $37.50 \pm 3.27^{\mathrm{c}}$ & $0.006 \pm 0.002$ & $9.69 \pm 2.85^{\mathrm{bc}}$ \\
\hline Mean \pm SD & & $0.17 \pm 0.14$ & $0.13 \pm 0.11$ & $73.13 \pm 7.12$ & $0.04 \pm 0.03$ & $28.32 \pm 7.51$ & $0.03 \pm 0.02$ & $25.20 \pm 31.87$ \\
\hline
\end{tabular}

${ }^{\mathrm{a}-\mathrm{d}}$ Values with different letters in the same column and study (in vitro or in vivo) differ significantly $(P<0.05)$.

${ }^{1}$ Amount of amoxicillin in skim milk, cream, and casein obtained from $1 \mathrm{~g}$ of whole milk.

${ }^{2}$ Limit of quantification.

the loss of milk and its products due to the presence of drug residues.

In the in vivo study, amoxicillin accumulated more in skim milk, whereas tylosin persisted in cream. In studies conducted on dairy animals such as cows and goats, lipophilic drugs, including triclabendazole, closantel, chloramphenicol, and rafoxanide, accumulate more in cream, whereas hydrophilic drugs such as benzylpenicillin and levamisole accumulate more in skim milk (Ziv and Rasmussen, 1975; Power et al., 2012, 2013a,b,c). We hypothesize that even though amoxicillin does not have a high binding degree to casein, the high accumulation ratio of amoxicillin in skim milk may be related to its hydrophilicity. Similarly, benzylpenicillin binds to casein at a low degree (Ziv and Rasmussen, 1975). In addition, in our study, the mean casein:whole milk ratio of amoxicillin was $25 \%$.

In dairy cows, Power et al. (2012) found that hydrophilic levamisole and lipophilic oxyclozanide accumulate more in skim milk than cream because they bound to whey protein. In a study conducted in cattle, the concentration of the lipophilic drug florfenicol in skim milk was approximately twice that in cream (Power et al., 2014). In contrast, in another study, the hydrophilic drug dihydrostreptomycin accumulated more in cream (Ziv and Rasmussen, 1975). The difference between

Table 3. Distribution (\%; mean $\pm \mathrm{SD}$ ) and amount ${ }^{1}(\mu \mathrm{g}$; mean $\pm \mathrm{SD})$ of tylosin in milk fractions following its addition to whole milk at different concentrations (in vitro study) or at different sampling times following a single intramuscular dose (15 mg/kg; in vivo study)

\begin{tabular}{|c|c|c|c|c|c|c|c|c|}
\hline Variable & $\mathrm{n}$ & Whole milk & \multicolumn{6}{|c|}{ Fraction } \\
\hline 0.05 & 9 & $0.05 \pm 0.00$ & $0.04 \pm 0.00$ & $93.52 \pm 0.87^{\mathrm{a}}$ & $<\mathrm{LOQ}^{2}$ & $<\mathrm{LOQ}$ & $<\mathrm{LOQ}$ & $<\mathrm{LOQ}$ \\
\hline 0.5 & 9 & $0.48 \pm 0.01$ & $0.45 \pm 0.01$ & $93.43 \pm 0.97^{\mathrm{a}}$ & $0.03 \pm 0.01$ & $6.93 \pm 1.02^{\mathrm{a}}$ & $0.01 \pm 0.00$ & $2.33 \pm 0.14^{\mathrm{a}}$ \\
\hline 5 & 9 & $4.75 \pm 0.02$ & $4.49 \pm 0.03$ & $94.64 \pm 0.72^{\mathrm{b}}$ & $0.27 \pm 0.04$ & $5.65 \pm 0.76^{\mathrm{b}}$ & $0.09 \pm 0.01$ & $2.00 \pm 0.12^{\mathrm{b}}$ \\
\hline \multicolumn{9}{|l|}{ In vivo study } \\
\hline \multicolumn{9}{|c|}{ Sampling time (h) } \\
\hline 24 & 6 & $0.14 \pm 0.001$ & $0.08 \pm 0.001$ & $56.88 \pm 2.11^{\mathrm{a}}$ & $0.06 \pm 0.005$ & $45.44 \pm 2.22^{\mathrm{a}}$ & $0.05 \pm 0.002$ & $34.61 \pm 15.07$ \\
\hline 48 & 6 & $0.09 \pm 0.001$ & $0.04 \pm 0.002$ & $44.65 \pm 2.22^{\mathrm{ab}}$ & $0.05 \pm 0.001$ & $58.34 \pm 2.34^{\mathrm{ab}}$ & $0.016 \pm 0.001$ & $18.59 \pm 14.76$ \\
\hline 72 & 6 & $0.06 \pm 0.003$ & $0.02 \pm 0.002$ & $36.28 \pm 2.22^{\mathrm{bc}}$ & $0.04 \pm 0.001$ & $67.16 \pm 2.34^{\mathrm{bc}}$ & $0.019 \pm 0.004$ & $29.55 \pm 6.42$ \\
\hline 96 & 6 & $0.047 \pm 0.002$ & $0.01 \pm 0.001$ & $21.81 \pm 2.35^{\mathrm{c}}$ & $0.039 \pm 0.001$ & $82.41 \pm 2.47^{\mathrm{c}}$ & $0.013 \pm 0.001$ & $28.36 \pm 16.21$ \\
\hline Mean \pm SD & & $0.08 \pm 0.004$ & $0.04 \pm 0.003$ & $39.90 \pm 14.74$ & $0.05 \pm 0.001$ & $63.34 \pm 15.53$ & $0.02 \pm 0.001$ & $27.78 \pm 6.70$ \\
\hline
\end{tabular}

\footnotetext{
${ }^{\mathrm{a}-c}$ Values with different letters in the same column and study (in vitro or in vivo) differ significantly $(P<0.05)$.
}

${ }^{1}$ Amount of tylosin in skim milk, cream, and casein obtained from $1 \mathrm{~g}$ of whole milk.

${ }^{2}$ Limit of quantification. 
these 2 studies may be related to degree of milk protein binding of the drugs.

Triclabendazole and its lipophilic metabolites were reported to accumulate more in cream and butter in cows (Power et al., 2013a). In the same study, the accumulation of the drug in cream and butter was found to depend on the dose. In another study, lipophilic drugs such as closantel and rafoxanide accumulated approximately 10-fold more in cream than skim milk (Power et al., 2013c).

During the in vivo stage of the current study, the lipophilic drug tylosin accumulated more in cream than

a)

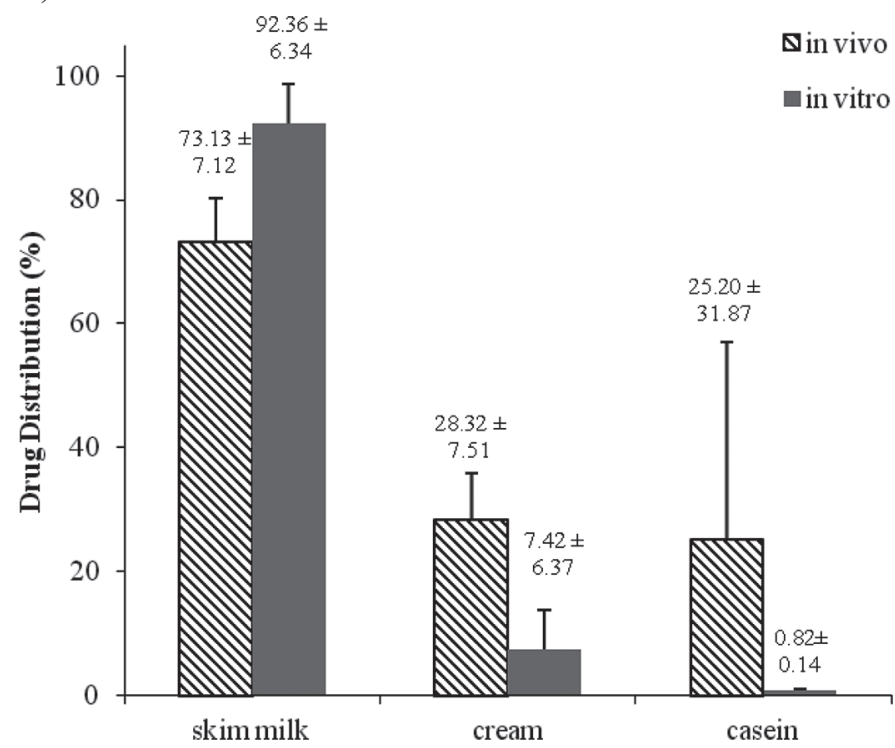

b)

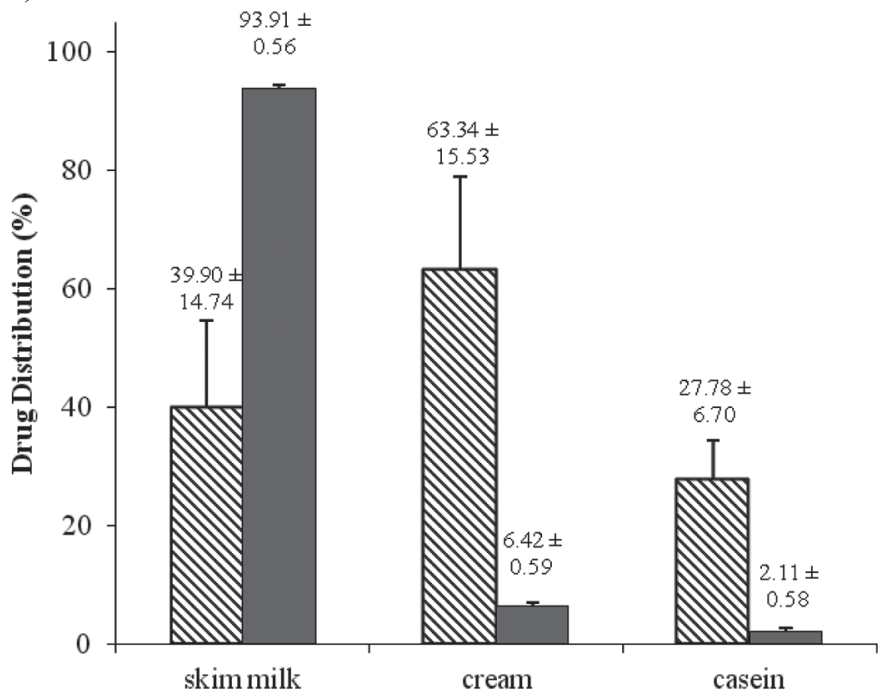

Figure 1. The distribution of (a) amoxicillin, and (b) tylosin in skim milk, cream, and casein in in vitro and in vivo studies (mean \pm $\mathrm{SD})$. in skim milk except at $24 \mathrm{~h}$ after injection, although the level of accumulation in cream was not at the predicted level. This may be related to the binding degree of the tylosin to casein and its zwitterion property (Ashraf and Aqma, 2017). The MRL of tylosin for milk is 50 $\mu \mathrm{g} / \mathrm{kg}$. Our results showed that the concentration of tylosin at $48 \mathrm{~h}$ in skim milk and cream and at $24 \mathrm{~h}$ in casein was $50 \mu \mathrm{g} / \mathrm{kg}$ or less.

The concentration of amoxicillin in milk and milk fractions fluctuated with sampling time. This fluctuation (biphasic disposition) may be related to the rapid absorption and slow excretion rate of amoxicillin. In another research conducted on cattle, it was determined that the plasma and milk concentration-time curves associated with i.m. administration of amoxicillin also fluctuated (Ozdemir et al., 2018).

The in vitro study shown that hydrophilic amoxicillin and lipophilic tylosin accumulated more in skim milk than in cream. When amoxicillin was spiked at a high concentration, accumulation in cream decreased, perhaps due to saturation. Similar to our results for amoxicillin, Hakk et al. (2016) determined that hydrophilic drugs such as oxytetracycline and penicillin $\mathrm{G}$ accumulate more in skim milk than in the milk fat fraction. In that study, sulfadimethoxine and ketoprofen, which are hydrophilic, accumulated equally between skim milk and milk fat. Although thiabendazole and ivermectin were reported to accumulate more in cream, we found that tylosin accumulated more in skim milk. In an in vitro study, it was reported that hydrophilic drugs such as aspirin and ciprofloxacin were distributed more in skim milk, whereas lipophilic drugs such as phenylbutazone, flunixin, and praziquantal were distributed more in milk fat. However, in the same study, lipophilic drugs such as thiamphenicol and acetaminophen were determined to be less dispersed in milk fat (Lupton et al., 2018). These differences may be related to the lipophilicity and ionization of the drug. The high accumulation of tylosin in skim milk may be related to its high binding affinity for milk proteins, as the percentage protein in whole milk $(3.10 \%)$ and skim milk $(3.19 \%)$ were higher than that in cream $(1.68 \%)$. In the in vitro medium, tylosin is bound to milk proteins more than plasma proteins (Al Wabel, 2008). Drugs that are bound to casein may accumulate more in skim milk (Ziv and Rasmussen, 1975). The concentration of tylosin in casein was $28 \%$ of the concentration in whole milk in our in vivo study. The degree of tylosin binding to milk protein was reported to be $15 \%$ in another study (Ziv and Sulman, 1973). Although lipophilic drugs bind to plasma and tissue proteins at a high degree (Marczak et al., 2015), the binding ratios of drugs to milk and plasma proteins may be different (Atkinson and Begg, 1990). Also, the binding affinities of drugs to 
milk proteins such as casein and whey protein were determined to be independent of the drugs' lipophilic and hydrophilic properties in an in vitro study (Lupton et al., 2018). The percentage distributions of both drugs to the casein fraction were similar in our in vitro study, but distribution of both drugs was $\sim 10$ times higher by in vivo measurement. Similar to previous research, the concentration of amoxicillin and tylosin associated with casein in our study depended on milk drug concentrations. The concentration of drugs in casein may be related to the method of obtaining the casein, such as acidification and renneting.

In summary, when the limited number of studies conducted in this area and results of the current study are evaluated, we can state that drugs that are hydrophilic or bind to casein accumulate in the skim milk fraction of milk, whereas lipophilic drugs distribute more in cream and butter. Studies should be conducted in vivo to demonstrate the distribution of drugs in different fractions of milk because, whereas amoxicillin distributed in the same fraction of milk, tylosin accumulated in different fractions of milk. Additional studies with sensitive analysis methods such as HPLC-MS are needed to determine accurate withdrawal times of amoxicillin in different milk fractions (e.g., cream and casein). The concentration of amoxicillin may be lower in butter than in cream because approximately $30 \%$ of cream is milk. In this study, the concentration of tylosin in milk was $40 \mu \mathrm{g} / \mathrm{kg}$ at $96 \mathrm{~h}$, which is less than the MRL. However, tylosin was present at the MRL in casein at $24 \mathrm{~h}$ and in skim milk and cream at $48 \mathrm{~h}$. The recalculation of determined withdrawal time and MRL in milk for the other milk fractions may help reduce economic losses.

\section{ACKNOWLEDGMENTS}

This research is supported by SUBAPK (17202008, Selcuk University Scientific Research Projects Coordination Unit, Konya, Turkey) and the paper was summarized from the $\mathrm{PhD}$ thesis of the first named author. The authors thank Anatolian Chemical and Industrial Corporation (Konya, Turkey) for their valuable cooperation during the study. The abstract of this article was presented as an oral presentation at the International Conference on Raw Material to Processed Foods, April 11-13, 2018, Antalya, Turkey.

\section{REFERENCES}

Agatonovic-Kustrin, S., L. Ling, S. Tham, and R. Alany. 2002. Molecular descriptors that influence the amount of drugs transfer into human breast milk. J. Pharm. Biomed. Anal. 29:103-119.
Al Wabel, N. 2008. The pharmacokinetics and milk residual behaviour of tylosin in lactating Najdi ewes. Majallah-i Tahqiqat-i Dampizishki-i Iran 9:138-143.

Anderson, K. L., W. Moats, J. Rushing, D. Wesen, and M. Papich. 1996. Ampicillin and amoxicillin residue detection in milk, using microbial receptor assay (Charm II) and liquid chromatography methods, after extra-label administration of the drugs to lactating cows. Am. J. Vet. Res. 57:73-78.

AOAC International. 2000. Official Methods of Analysis. 17th ed. AOAC International, Gaithersburg, MD. Accessed Sep. 26, 2018. http://www.fao.org/docrep/006/Y5022E/y5022e03.htm \#TopOfPage.

Ashraf, M. A., and W. S. Aqma. 2017. Environmental Conservation, Clean Water, Air and Soil (CleanWAS). IWA Publishing, London, UK.

Atef, M., S. A. H. Youssef, A. H. Atta, and A. A. El-Maaz. 1991. Disposition of tylosin in goats. Br. Vet. J. 147:207-215.

Atkinson, H. C., and E. J. Begg. 1990. Prediction of drug distribution into human milk from physicochemical characteristics. Clin. Pharmacokinet. 18:151-167.

Avci, T., and M. Elmas. 2014. Milk and blood pharmacokinetics of tylosin and tilmicosin following parenteral administrations to cows. ScientificWorldJournal 2014:869096

Benchaoui, H. 2010. Population medicine and control of epidemics. Pages 113-138 in Comparative and Veterinary Pharmacology. Springer, Berlin, Germany.

Carceles, C. M., E. Escudero, and J. Baggot. 1995a. Comparative pharmacokinetics of amoxicillin/clavulanic acid combination after intravenous administration to sheep and goats. J. Vet. Pharmacol. Ther. 18:132-136.

Carceles, C. M., E. Escudero, M. Vicente, J. Serrano, and S. Carli. 1995b. Pharmacokinetics of amoxicillin/clavulanic acid combination after intravenous and oral administration in goats. Vet. Q. $17: 134-138$.

Craig, C. R., and R. E. Stitzel. 2004. Metabolism and excretion of drugs. Page 45 in Modern Pharmacology with Clinical Applications. 5th ed. Lippincott Williams \& Wilkins, Philadelphia, PA.

Craigmill, A. L., M. Pass, and S. Wetzlich. 1992. Comparative pharmacokinetics of amoxicillin administered intravenously to sheep and goats. J. Vet. Pharmacol. Ther. 15:72-77.

Dudriková, E., S. Jozef, and N. Jozef. 1999. Liquid chromatographic determination of tylosin in mastitic cow's milk following therapy. J. AOAC Int. 82:1303-1307.

Elsheikh, H. A., A. Taha, A. Khalafalla, I. Osman, and I. Wasfi. 1999. Pharmacokinetics of amoxicillin trihydrate in Desert sheep and Nubian goats. Vet. Res. Commun. 23:507-514.

Escudero, E., C. Carceles, and S. Vicente. 1996. Pharmacokinetics of amoxicillin/ciavulanic acid combination and of both drugs alone after intravenous administration to goats. Br. Vet. J. 152:551-559.

European Union. 2010. Commission Regulation No. 37/2010 of 22 December 2009 on pharmacologically active substances and their classification regarding maximum residue limits in foodstuffs of animal origin. Accessed Sep 10, 2018. https://ec.europa.eu/ health/sites/health/files/files/eudralex/vol-5/reg_2010_37/reg _2010_37_en.pdf.

Fernandez, C., P. Modamio, N. Mestorino, J. Errecalde, and E. Marino. 2007. Pharmacokinetics of sodium and trihydrate amoxicillin in sheep after intravenous and intramuscular administration. J. Vet. Pharmacol. Ther. 30:263-266.

Gehring, R., and G. Smith. 2006. An overview of factors affecting the disposition of intramammary preparations used to treat bovine mastitis. J. Vet. Pharmacol. Ther. 29:237-241.

Hakk, H., N. W. Shappell, S. J. Lupton, W. L. Shelver, W. Fanaselle, D. Oryang, C. Y. Yeung, K. Hoelzer, Y. Ma, and D. Gaalswyk. 2016. Distribution of animal drugs between skim milk and milk fat fractions in spiked whole milk: Understanding the potential impact on commercial milk products. J. Agric. Food Chem. 64:326-335.

Hervada, A. R., E. Feit, and R. Sagraves. 1978. Drugs in breast milk. Perinat. Care 2:19-25.

Karageorgou, E. G., and V. F. Samanidou. 2011. Development and validation according to European Union Decision 2002/657/EC of 
an HPLC-DAD method for milk multi-residue analysis of penicillins and amphenicols based on dispersive extraction by QuEChERS in MSPD format. J. Sep. Sci. 34:1893-1901.

Khaskheli, M., R. Malik, M. Arain, A. Soomro, and H. Arain. 2008 Detection of $\beta$-lactam antibiotic residues in market milk. Pak. J. Nutr. 7:682-685.

Li, H., G. Q. Wu, S. S. Tang, X. L. Xiao, and J. C. Li. 2014. Pharmacokinetics and pharmacodynamics of a novel amoxicillin/sulbactam/prednisolone intramammary infusion in lactating cows after repeated administrations. Vet. Med. 59:221-229.

Luo, W. E. B. Hansen, C. Y. Ang, J. Deck, J. P. Freeman, and H. C. Thompson. 1997. Simultaneous determination of amoxicillin and ampicillin in bovine milk by HPLC with fluorescence detection. J. Agric. Food Chem. 45:1264-1268.

Lupton, S. J., N. W. Shappell, W. L. Shelver, and H. Hakk. 2018. Distribution of spiked drugs between milk fat, skim milk, whey, curd, and milk protein fractions: Expansion of partitioning models. J. Agric. Food Chem. 66:306-314.

Marczak, M., K. M. Okoniewska, J. Okoniewski, T. Grabowski, and J. J. Jaroszewski. 2015. Indirect relationship between lipophilicity and maximum residue limit of drugs determined for fatty tissue. Bull. Vet. Inst. Pulawy 59:383-391.

Martínez-Huelamo, M., E. Jiménez-Gámez, M. P. Hermo, D. Barrón and J. Barbosa. 2009. Determination of penicillins in milk using LC-UV, LC-MS and LC-MS/MS. J. Sep. Sci. 32:2385-2393.

McEwen, S. A., and P. J. Fedorka-Cray. 2002. Antimicrobial use and resistance in animals. Clin. Infect. Dis. 34(Suppl_3):S93-S106.

Morton, R. K. 1954. The lipoprotein particles in cow's milk. Biochem. J. $57: 231-237$

NRC (National Research Council). 1988. Designing Foods: Animal Product Options in the Marketplace. National Acad. Press, Washington, DC. https://doi.org/10.17226/1036.

Ozdemir, Z., B. Tras, K. Uney, H. Eser Faki, and T. M. Besoluk. 2018. Determination of milk/plasma ratio and milk and plasma pharmacokinetics of amoxicillin after intramuscular administration in lactating cows. J. Vet. Pharmacol. Ther. https://doi.org/10.1111/ jvp.12713.

Phelan, M., A. Aherne, R. J. FitzGerald, and N. M. O'Brien. 2009 Casein-derived bioactive peptides: Biological effects, industrial uses, safety aspects and regulatory status. Int. Dairy J. 19:643-654.

Phillips, I., M. Casewell, T. Cox, B. De Groot, C. Friis, R. Jones, C. Nightingale, R. Preston, and J. Waddell. 2004. Does the use of antibiotics in food animals pose a risk to human health? A critical review of published data. J. Antimicrob. Chemother. 53:28-52.

Power, C., M. Danaher, R. Sayers, B. O'Brien, C. Clancy, A. Furey, and K. Jordan. 2013a. Investigation of the migration of triclabendazole residues to milk products manufactured from bovine milk, and stability therein, following lactating cow treatment. J. Dairy Sci. 96:6223-6232.

Power, C., M. Danaher, R. Sayers, B. O'Brien, M. Whelan, A. Furey, and K. Jordan. 2013b. Investigation of the persistence of rafoxanide residues in bovine milk and fate during processing. Food Addit. Contam. Part A Chem. Anal. Control Expo. Risk Assess. 30:1087-1095.

Power, C., R. Sayers, M. Danaher, M. Moloney, B. O'Brien, A. Furey and K. Jordan. 2014. Investigation of the persistence of florfenicol residues in bovine milk and fate during processing. Int. Dairy J. $39: 270-275$

Power, C., R. Sayers, B. O'Brien, Y. Bloemhoff, M. Danaher, A. Furey, and K. Jordan. 2012. Partitioning of nitroxynil, oxyclozanide and levamisole residues from milk to cream, skim milk and skim milk powder. Int. J. Dairy Technol. 65:503-506.

Power, C., R. Sayers, B. O'Brien, C. Clancy, A. Furey, K. Jordan, and M. Danaher. 2013c. Investigation of the persistence of closantel residues in bovine milk following lactating-cow and dry-cow treatments and its migration into dairy products. J. Agric. Food Chem. 61:8703-8710

Reyns, T., S. De Boever, S. De Baere, P. De Backer, and S. Croubels. 2008. Tissue depletion of amoxicillin and its major metabolites in pigs: Influence of the administration route and the simultaneous dosage of clavulanic acid. J. Agric. Food Chem. 56:448-454.

Wang, H., R. Zhang, H. Duan, and Y. Yao. 2008. Simultaneous determination of tilmicosin, tylosin and spiramycin residues in milk by HPLC. Chin. J. Anal. Lab. 7:98-101.

Yeoman, G. 1977. Microbiology and bioavailability of amoxicillin. Vet. Med. Small Anim. Clin. 72:720-738.

Ziv, G., and F. Rasmussen. 1975. Distribution of labeled antibiotics in different components of milk following intramammary and intramuscular administrations. J. Dairy Sci. 58:938-946.

Ziv, G., and F. Sulman. 1973. Serum and milk concentrations of spectinomycin and tylosin in cows and ewes. Am. J. Vet. Res. 34:329333. 